\title{
O USO DA TECNOLOGIA DE IMPRESSÃO 3D NA EDUCAÇÃO: PRESSUPOSTOS CONCEITUAIS A PARTIR DA TEORIA DO DUPLO ASPECTO DE ANDREW FEENBERG
}

\author{
Alex Calazans ${ }^{1}$ \\ Caio Alberto Martins ${ }^{2}$
}

\begin{abstract}
Resumo:
Feenberg apresenta a teoria do duplo aspecto como uma forma de abordar a natureza de objetos técnicos. Isso, por sua vez, tem relação com sua concepção de que a tecnologia não é neutra e nem determinada. Para ele, tal teoria possui uma dupla dimensão que envolve, além do conhecimento técnico, aspectos sociais de objetos técnicos. Assim, o uso da tecnologia, a partir dos valores impregnados nela, torna possível um aprimoramento de seu produto. Neste trabalho, pretende-se analisar essa relação a partir da tecnologia de Impressão 3D, considerando o contexto específico da educação. Trata-se de compreender, a partir do que o duplo aspecto estabelece, algumas das demandas necessárias para que o uso de tal impressão, no processo educativo, promova uma compressão adequada da tecnologia, permitindo a sua democratização. Outro conceito que Feenberg apresenta é o de democratização da tecnologia. A Impressora 3D passa por constantes aprimoramentos e está se tornando mais acessível em vista da popularização do uso de sua tecnologia. Contudo, mais do que permitir acesso à tecnologia, a democratização está relacionada a vários elementos, dentre elas a possibilidade de uma diversificação da tecnologia, possibilitando soluções técnicas distintas e modos de vidas distintos. Contudo, para que isso se estabeleça, aparece junto a demanda de uma compreensão diferente da natureza e uso da tecnologia. Assim, o que é necessário levar em consideração para que o uso de Impressão 3D, na educação, promova um avanço democrático no modo como se compreende a tecnologia em um sentido geral?
\end{abstract}

Palavras-chave: Feenberg. Teoria do duplo aspecto. Tecnologia. Impressão 3D.

\section{THE USE OF 3D PRITING TECHNOLOGY IN EDUCATION: CONCEPTUAL ASSUMPTIONS FROM THE DOUBLE ASPECT THEORY OF ANDREW FEENBERG}

\begin{abstract}
:
Feenberg presents the Double Aspect Theory as a way of approaching the nature of technical objects. This, in turn, is related to his view that technology is neither neutral nor determined. For him, such theory has a double dimension which involves, in addition to technical knowledge, social aspects of technical objects. Thus, the use of technology, based on its values imbued in it, makes it possible to improve its product. In this work, we intend to analyze this relationship from the $3 \mathrm{D}$ Printing technology, considering the specific context of education. It is about understanding, from what the double aspect establishes, some of the necessary demands for the use of such printing, in the educational process, to promote an adequate compression of the technology, allowing its democratization. Another concept that Feenberg presents is the democratization of technology. The 3D Printer undergoes constant improvement and is becoming more affordable in view of the popularization of the use of its technology. However, more than allowing access to technology, democratization is related to the defense of a diversification of technology, enabling different ways of life. However, for this to be established, there is a demand for a different understanding of the nature and use of technology. So, what needs to be taken into account for the use of $3 \mathrm{D}$ printing, in education, to promote a democratic advance in the way technology is understood?
\end{abstract}

Keywords: Feenberg. Double Aspect Theory. Technology. 3D Printing.

1 Doutor em Filosofia pela UNICAMP, professor de filosofia na Universidade Tecnológica Federal do Paraná (UTFPR) e no programa de Mestrado Profissional em Filosofia (PROF-FILO), da Universidade Federal do Paraná (UFPR). E-mail: filoalexcalazans@gmail.com. http://orcid.org/0000-0003-4569-3595

2 Mestrando do programa de Mestrado Profissional em Filosofia (PROF-FILO), da Universidade Federal do Paraná (UFPR). Professor de filosofia na rede pública estadual do Paraná. E-mail: caioalberto@gmail.com. http://orcid.org/0000-0002-2245-8843 


\section{INTRODUÇÃ̃}

Feenberg defende uma abordagem da tecnologia na qual se recusa a interpretação de que ela seja neutra, independente dos interesses humanos ou, ainda, determinada por elementos puramente técnicos. A proposta de Feenberg aponta para uma avaliação da natureza de objetos técnicos a partir do que ele denomina como teoria do duplo aspecto: "Chamarei essa abordagem da teoria do poder/conhecimento ou da ideologia/ciência como 'duplo aspecto' porque trata as funções hegemônicas e cognitivas como aspectos complementares de uma única fonte subjacente, em vez de coisas separadas" (FEENBERG, 2002, p. 75). Em outras palavras, ambos aspectos - valores cognitivos (científicos e técnicos) e valores sociais (interesses sociais) - estão presentes simultaneamente na tecnologia. $\mathrm{O}$ aspecto técnico não esgota o que seria uma dada tecnologia. Desse modo, a neutralidade não seria possível, já que se reconhece nos próprios objetos tecnológicos aceitos algo que reflete interesses sociais hegemônicos.

A filosofia da tecnologia, defendida por Feenberg, vem acompanhada da análise de vários casos de usos da tecnologia: a menção à história da bicicleta, do computador (Minitel) e até mesmo das caldeiras usadas em barcos, no século XIX, nos Estados Unidos. ${ }^{3}$ Tal atitude contempla, ainda, questões acerca da educação. Em vários momentos Feenberg aborda o uso da tecnologia no contexto do processo educativo. Por exemplo, em suas reflexões sobre o impacto do uso da internet, aparece uma abordagem do problema da automação na educação ${ }^{4}$. Há, com isso, o contato direto de seu pensamento com uma agenda de pesquisa na área de educação ainda não esgotada, uma vez que a relação entre educação e tecnologia se abre para inúmeras outras possibilidades de aplicações de aparatos tecnológicos. $\mathrm{O}$ avanço da utilização da tecnologia por educadores tem sido incentivado por várias fontes, dentre elas, inclusive, por ações governamentais, buscando estratégias de capacitação dos estudantes para o uso e desenvolvimento de tecnologias requeridas na atualidade. Esse é o caso da tecnologia conhecida como impressão 3D, que está sendo popularizada com grande intensidade. Cada vez mais as impressoras que produzem objetos em formato 3D estão presente no cotidiano das pessoas.

Nesse sentido, o que será investigado aqui diz respeito a uma avaliação da tecnologia de impressão 3D, considerando a concepção feenbergiana do duplo aspecto. Se tal tecnologia, ao empregá-la na educação, deve ser concebida a partir da presença tanto da

3 Feenberg se utiliza de exemplos tecnológicos para estabelecer análises e construções argumentativas diversas. Quanto ao uso dos exemplos mencionados: cf. FEENBERG, $2010 \mathrm{~b}$.

4 Acerca desse problema: cf. FEENBERG, 2002, p. 114-130.

\begin{tabular}{|c|c|c|c|c|}
\hline Revista Didectus & Ano 10 & n. 23 & Maio - Agosto 2021 & p. $33-53$ \\
\hline
\end{tabular}


instância técnica quanto da social, surge a demanda de expor com mais detalhes alguns dos pressupostos filosóficos da própria relação entre educação e tecnologia. Cabe investigar em qual sentido a teoria do duplo aspecto contribui para orientar o uso da impressão 3D na educação. Especificamente, podemos formular a seguinte pergunta que norteará a investigação: qual é o nível de importância que educadores devem dar ao aspecto técnico da impressão 3D, na tentativa de compreender os elementos sociais também ali envolvidos?

\section{FEENBERG E O DUPLO ASPECTO DA TECNOLOGIA}

\subsection{Abordagem da teoria crítica da tecnologia}

O filósofo norte-americano Andrew Lewis Feenberg (1943-) concebe a tecnologia a partir de uma perspectiva conhecida como teoria crítica da tecnologia. Para compreender do se trata, Feenberg sugere a possibilidade de construir interpretações sobre o que é a tecnologia a partir de dois eixos, que refletiriam a relação entre valores humanos (sejam éticos, políticos etc.) e poderes humanos (considerando a capacidade humana de intervir no desenvolvimento tecnológico). Assim, a teoria crítica seria uma das possibilidades de definir a tecnologia, incluindo-se outras três: o determinismo, o instrumentalismo e o substantivismo. ${ }^{5}$

Sobre o determinismo, Feenberg explica que "os deterministas acreditam que a tecnologia não é controlada humanamente, mas que, pelo contrário, controla os seres humanos" e que isso "molda a sociedade às exigências de eficiência e progresso"7, tornando universal esse uso tecnológico para qualquer necessidade humana. O que está em questão, considerando também o que Dagnino (2008, p. 51-52) afirma sobre o determinismo tecnológico, é a concepção de que a tecnologia evolui de modo linear, alimentada pela força da eficiência, sendo neutra e livre de intervenções sociais, quaisquer que sejam elas. Há, portanto, uma espécie de subordinação no modo de ser da sociedade ao processo de desenvolvimento técnico (que é autônomo), realizado pela tecnologia. Assim, o social subordina-se aos aspectos técnicos, tidos de modo puro, por serem supostamente compreendidos como independentes de elementos sociais.

O instrumentalismo, segundo Feenberg, “é a visão-padrão moderna, segundo a qual a tecnologia é simplesmente uma ferramenta ou instrumento com que a espécie humana satisfaz

\footnotetext{
5 Cf. FEENBERG, 2010a. p. 59.

6 Ibidem.

7 Ibidem.
}

\begin{tabular}{|l|l|l|l|l|}
\hline Q & Anotista 10 & n. 23 & Maio - Agosto 2021 & p. 33 - 53 \\
\hline
\end{tabular}


suas necessidades" ". Já que as necessidades humanas são admitidas como guia, a tecnologia constitui-se como meio para alcançar tais fins. O resultado disso é uma concepção de que a tecnologia, em si, é desprovida dos valores humanos. Um objeto técnico seria um puro instrumento, algo neutro quanto aos interesses humanos. Os valores humanos só entrariam em questão quando considerados os usos realizados a partir das necessidades a serem supridas. Nesse sentido, há um controle humano da tecnologia. Ela é modificada de acordo com a finalidade estabelecida pelo humano. Contudo, em sua natureza, permaneceria a neutralidade quanto a valores sociais.

Além disso, há a visão do substantivismo, na tecnologia. Tal visão assume que "a tecnologia está, de certo modo, carregada de valores" "9 que podem ser transferidos para a esfera humana:

[...] os valores contidos na tecnologia são exclusivos da tecnologia. Eles incluem a eficiência e o poder, metas que pertencem a qualquer e a todo sistema técnico. $\mathrm{Na}$ medida em que usamos a tecnologia, estamos comprometidos com o mundo em um movimento de maximização e controle. Essa aproximação do mundo determina um estilo tecnológico de vida (FEENBERG, 2010a, p. 62).

A tese sustentada é a de que existem valores que advêm da própria natureza da tecnologia e, sendo objetivos, eles podem ser usados na constituição de um modo de vida social. Aqui não se pode confundir o substantivismo com a visão do determinismo. Mesmo que sutis, há diferenças entre eles. Neste último, em um sentido absoluto, só se aceita o domínio técnico como sendo o que constitui a tecnologia; e isso determina como a tecnologia se apresenta em um meio social. Diferentemente disso, naquele, ou seja, no substantivismo, Feenberg indica que há valores específicos da tecnologia que, de certa forma, têm ao mesmo tempo um estatuto social, e que modelam o modo de ser da sociedade. Uma visão substantivista pode assumir, como ponto de partida, que os aspectos técnicos são também de alguma forma sociais, pois podem moldar a vida social. Essa visão social, do aspecto técnico, nem sempre está presente na visão determinista, porque no discurso determinista aparecem argumentos que defendem uma espécie de neutralidade do que é técnico, considerando o que é social. O determinismo, ao contrário do substantivismo, tem uma visão próxima da neutralidade tecnológica.

Como um crítico dessas três visões, Feenberg apresenta outra possibilidade de interpretação da tecnologia, na qual ele se insere: trata-se da teoria crítica da tecnologia. De

Ibidem, p. 58.

Ibidem, p. 62.

\begin{tabular}{|c|c|c|c|c|}
\hline Gevista Qialectus & Ano 10 & n. 23 & Maio - Agosto 2021 & p. 33 - 53 \\
\hline
\end{tabular}


modo geral, Feenberg (Ibidem, p. 61) apresenta as principais características de sua abordagem, podendo ser enumeradas da seguinte maneira: (i) os seres humanos podem transformar a sociedade tecnológica onde vivem em um lugar melhor, sem necessitar de uma intervenção externa a eles - como seria o caso de uma interpretação religiosa, que pressupõe uma ação realizada por um Deus; (ii) reconhece-se que a tecnologia pode ter consequências catastróficas contra o ser humano e a natureza, contudo, observa-se que a tecnologia pode também representar "maior liberdade"10; (iii) a tecnologia não representa um problema, mas sim a falta de instituições adequadas para o "controle humano" da tecnologia. Segundo Cruz (2020, p. 105106), o que está em jogo é o fato de que o desenvolvimento tecnológico se manifesta em um espaço propriamente político, ou seja, "é uma arena política a ser disputada; e disputa que, dependendo do seu resultado, pode implicar um ordenamento sociopolítico menos ou mais próximo daquele por que possamos estar lutando". Nesse sentido, a tecnologia não está desconectada do contexto sociopolítico. Ela passa a ser vista como um campo no qual se estabelece a possibilidade de configurações políticas. Modos de vida distintos podem se revelar, dependendo das opções tecnológicas que se manifestam, reforçando ou não concepções sociais (éticas ou políticas) hegemônicas. Assim, dependendo do que se aceita tecnologicamente, há, portanto, a inclusão ou não de mais pessoas no controle da própria tecnologia. A democracia pode ser pensada e avaliada a partir da própria tecnologia, pois sempre há valores presentes nela:

[...] os valores incorporados à tecnologia são socialmente específicos e não são representados adequadamente por tais abstrações como a eficiência ou o controle. A tecnologia não molda apenas um, mas muitos possíveis modos de vida, cada um dos quais reflete escolhas distintas de objetivos e extensões diferentes da mediação tecnológica. (FEENBERG, 2010a, p. 62).

As concepções abstratas criticadas aqui, "eficiência ou controle", dizem respeito a interpretações, como a visão substantivista da tecnologia, na qual se defende a ideia de que há um valor universal, válido para a avaliação de qualquer tecnologia. No caso da eficiência, tem uma relação com o desempenho de uma determinada tecnologia em alcançar determinados fins. No entanto, a crítica de Feenberg se estabelece no sentido de que tal valor, concebido como

10 Feenberg reconhece que a visão substancialista da tecnologia, em alguns casos, revelou-se como uma visão pessimista, uma vez que, ao ser autônoma, pode submeter o ser humano a um de seus objetos. É nesse sentido que Feenberg faz menção ao romance de Huxley, Admirável mundo novo, como sendo uma espécie de denúncia dos possíveis efeitos maléficos da tecnologia, ao transformar os seres humanos em "meros dentes de engrenagem de maquinarias".

\begin{tabular}{|c|c|c|c|c|}
\hline Rovista Dialectus & Ano 10 & n. 23 & Maio - Agosto 2021 & p. $33-53$ \\
\hline
\end{tabular}


técnico, desconsidera que a própria eficiência necessita ser definida levando em conta os valores sociais que ela implica. Como nos lembra Cupani (2004, p. 510) acerca desse problema na filosofia de Feenberg, no capitalismo a eficiência da tecnologia é medida a partir do lucro, tentando ignorar, como meras "externalidades", implicações a respeito de questões sociais. Contudo, a própria noção de eficiência, uma vez que não é neutra, pode ser pensada de modo explícito a partir dos elementos sociais: “...a eficiência poderia ser diferentemente concebida num outro código social que respondesse a exigências da vida humana hoje não realizadas e que aparecem em forma de reinvindicações econômicas e morais [...]” (Ibidem). Portanto, a teoria crítica da tecnologia contém a defesa de uma concepção democrática da tecnologia, na qual as consequências sociais das escolhas tecnológicas devem ser debatidas. ${ }^{11}$

Segundo Cupani (2017, p. 159), a tecnologia, para Feenberg, é um fenômeno tipicamente moderno, no sentindo de que, quando ela surgiu, foi engendrado um debate sobre sua aceitação ou não, dando a impressão de que haveria uma distinção precisa entre o que é social e o que é tecnológico. Concebendo a tecnologia como uma estrutura material da modernidade, Feenberg se filia a um grupo de pensadores que avalia criticamente a sociedade moderna, que é pautada no desenvolvimento do capitalismo. É nesse sentido que se estabelece o vínculo conceitual com a teoria crítica, dos pensadores da escola de Frankfurt:

\begin{abstract}
A análise de Feenberg (que prolonga, criticamente, as da escola de Frankfurt) repousa em três pressuposições: que o projeto tecnológico é relativo ao seu contexto social; que a distribuição desigual de influência social sobre esse projeto contribui para a injustiça social; e que existem pelo menos alguns exemplos em que o envolvimento do público no projeto tecnológico de dispositivos e sistemas faz uma diferença sociopolítica (CUPANI, 2017, p. 160) ${ }^{12}$.
\end{abstract}

Portanto, a teoria crítica da tecnologia não é um projeto filosófico independente do questionamento do exercício do poder político. Ao avaliar a tecnologia, Feenberg está tentando

11 Cruz (2020, p. 111-112) resume a concepção de democratização da tecnologia, para Feenberg, considerando três modos distinto: 1) subversão do uso de uma dada tecnologia; 2) regulamentação do desenvolvimento da tecnologia; 3) associação com técnicos (as). Para os propósitos aqui, não é de interesse detalhar cada um desses modos. Contudo, é possível dizer que a crítica de Feenberg ao conceito de eficiência, como apresentado acima, está pressuposto em cada um desses modos de estabelecer a democratização da tecnologia. Esse é o caso, em especial, do modo (3), no qual Feenberg parece sugerir a constituição de associações de técnicos que buscam a construção de soluções técnicas em um diálogo com as pessoas diretamente afetadas por tais soluções. O conceito de eficiência, nesse sentido, apareceria moldado pelos valores sociais revelados em tal diálogo.

12 Cupani ainda descreve as críticas de Feenberg a algumas das teses fundamentais dos principais representes dessa escola. Quanto a Horkheimer, a Adorno e a Marcuse (que foi orientador de Feenberg no doutorado), ele argumenta contra o pessimismo relacionado à "transformação do sistema político". Quanto a Habermas, um dos representantes das novas gerações da escola de Frankfurt, Feenberg recusa a concepção habermasiana de ciência e tecnologia como puramente racionais, desprovidas da vida social. Para mais análises da aproximação (e afastamento) de Feenberg à teoria crítica dos pensadores de Frankfurt: cf. CRUZ, 2019, p. LVI-LXI.

\begin{tabular}{|l|l|l|l|c|}
\hline Revista Dialectus & Ano 10 & n. 23 & Maio - Agosto 2021 & p. 33 - 53 \\
\hline
\end{tabular}


conciliar esferas supostamente tratadas como distintas. No contato com exemplos reais, o emprego da tecnologia torna-se aspecto central para diagnosticar como a tecnologia, além de resultar em efeitos danosos para a sociedade, sofre também interferência vinda do âmbito social. Há uma concepção diferenciada da própria natureza dos objetos tecnológicos. A demanda por compreender como isso se fundamenta leva Feenberg a desenvolver uma análise conceitual da relação entre elementos técnicos e sociais da tecnologia. Especificamente, é isso que em partes está presente em sua teoria sobre o duplo aspecto, algo que será apresentado a seguir.

\subsection{Teoria do duplo aspecto}

A teoria de Feenberg sobre o duplo aspecto é desenvolvida em vários de seus escritos. Contudo, aparece como um de seus objetivos a tentativa de caracterizar a tensão conceitual a respeito do modo de definir a tecnologia, em si, considerando a relação entre o que é técnico e o que é social. A inspiração de Feenberg para formular sua teoria vem das abordagens de Foucault e Marcuse quanto à ciência e à tecnologia. Assim, o duplo aspecto surge como um desdobramento de conceitos desses autores. No caso de Foucault, a discussão sobre a relação entre poder/conhecimento permite a Feenberg compreender como formas modernas de opressão estariam baseadas em "verdades técnicas", selecionadas por um poder hegemônico que busca se manter nesse poder, reproduzindo-se a partir dessas mesmas verdades adotadas. ${ }^{13}$ Por outro lado, ao estabelecer que a ciência e a tecnologia são expressões de interesses de classes dominantes, quanto a Marcuse, manifesta-se o comprometimento com um tipo de ambiguidade. Trata-se do problema de que, ao se aceitar a ciência e a tecnologia, sempre aparecerá um aspecto de opressão. Não haveria a aceitação dessas áreas do conhecimento sem o comparecimento de atitudes opressivas. Isso também estaria presente na proposta de Foucault. ${ }^{14}$ Assim, Feenberg vê a necessidade de transformar tais concepções, pois elas se aproximam de uma visão substancialista da tecnologia. Portanto, sua teoria do duplo aspecto trata da possibilidade de configurar também uma imagem mais otimista da tecnologia, sem cair em ambiguidades no modo como concebê-la.

Em uma das abordagens de Feenberg da teoria do duplo aspecto, ela é apresentada em sua relação com os conceitos de função técnica e de significado dado socialmente aos objetos tecnológicos. Por função técnica, Feenberg (2010b, p. 81) entende a noção de

13 Cf. FEENBERG, 2010b, 82.

14 Não é o objetivo aqui desenvolver em detalhes a crítica que Feenberg realiza a esses dois autores. Para uma compreensão mais pormenorizada acerca do tema: cf. FEENBERG, 2002, p. 63-74.

\begin{tabular}{|l|l|l|l|l|}
\hline Qevista Dialectus & Ano 10 & n. 23 & Maio - Agosto 2021 & p. $33-53$ \\
\hline
\end{tabular}


racionalidade que pode separar os "objetos do seu contexto original para incorporá-los em sistemas teóricos e funcionais". Também denominada como "racionalidade funcional", a função técnica é um tipo de exercício da razão, a respeito de objetos técnicos, que aborda seus constituintes funcionais, sejam eles internos ou externos a tais objetos. O que parece estar em questão é a consistência técnica quanto à sua lógica operativa, que permite afirmar que uma tecnologia funciona. Essa análise, a partir da funcionalidade, resulta no que Feenberg compreende como sendo o isolamento em um dos contexto dos objetos tecnológicos:

A racionalidade funcional, como a racionalidade tecnocientífica em geral, isola objetos do seu contexto original para incorporá-los em sistemas teóricos ou funcionais. As instituições que dão suporte a esse procedimento - tal como laboratórios e centros de pesquisa - formam um contexto específico que dispõe de práticas próprias e ligações com os vários agentes sociais e áreas de poder [Itálico nosso] (FEENBERG, 2010b, p. 81-82).

É importante ressaltar que não se nega que objetos tecnológicos possuem elementos técnicos que podem ser capturados em um contexto específico. A racionalidade funcional se manifesta em um contexto criado, quando a atenção se volta ao objeto tecnológico na tentativa de teorizar seus esquemas de funcionamento. É isso que acontece na prática em laboratório. Contudo, Feenberg compreende que, mesmo se tratando de um elemento legítimo da análise desses objetos, há um limite. Tal isolamento, denominado por Feenberg como descontextualização, não resulta na constituição de uma racionalidade entendida como pura, de modo absoluto:

A noção de racionalidade pura surge quando o trabalho de descontextualização não foi compreendido suficientemente como sendo uma atividade social, que reflete interesses sociais. As tecnologias são selecionadas a partir de interesses entre muitas possíveis configurações (Ibidem, p. 81-82).

Trata-se do fato de que não há uma análise racional que esgote o que é um objeto tecnológico, estabelecendo os elementos teóricos gerais de funcionamento. Uma racionalidade pura, criada a partir da compreensão "descontextualizada”, não é possível, segundo Feenberg. Isso seria uma compreensão inadequada da prática da análise funcional do que é tecnológico.

É nesse sentido que aparece mais um elemento para análise: a questão do significado vinculado aos objetos tecnológicos, uma vez que não há descontextualização absoluta. A definiçãa de significado, à vista disso, leva em consideração o aspecto social do uso das tecnologias. Feenberg (2010b, p. 75-76) chega ainda a comparar tal abordagem àquela

\begin{tabular}{|c|c|c|c|c|}
\hline Q Rovista Dialeatus & Ano 10 & n. 23 & Maio - Agosto 2021 & p. $33-53$ \\
\hline
\end{tabular}


feita a artefatos culturais, sobre os quais se realizam interpretações, em sentido hermenêutico, buscando explicações sem desconsiderar os contextos nos quais estão inseridos.

Sendo assim, considerando a possibilidade de análise funcional e ainda do significado social, o duplo aspecto estabelece-se como uma tese metafísica, ou seja, apresentase como um critério para abordar adequadamente o ser dos objetos tecnológicos:

[...] o significado social e a racionalidade funcional são dimensões inextricavelmente entrelaçadas da tecnologia. Não são ontologicamente distintos, como o significado na mente do observador e a racionalidade própria da tecnologia, por exemplo. São, em lugar disso, aspectos duplos do mesmo objeto técnico básico, cada aspecto sendo revelado por um contexto específico [Itálico nosso] (ibidem, p. 81).

Portanto, Feenberg nega que o constituinte da tecnologia seja unicamente sua funcionalidade técnica. Ele recusa também que o aspecto social seria um elemento externo, presente somente na "mente do observador", pois isso abre as portas para uma visão neutra, “instrumental”, dos objetos técnicos. Diferentemente, a tecnologia se define pela presença, em seu ser, tanto de elementos sociais quanto de elementos técnicos. É evidente que eles não são apreendidos de imediato. Há a necessidade de observar que a apreciação dos contextos de análise se apresenta como um passo necessário para alcançar o modo correto de abordagem da tecnologia, pois, como Feenberg afirma, cada aspecto, em relação a esse duplo presente no objeto, revela-se em "um contexto específico". Logo, existe a demanda de compreender a análise dos objetos técnicos como um processo, pois ela depende desses vários contextos nos quais os objetos podem ser abordados.

Uma possibilidade de reforçar a compreensão do que seria o duplo aspecto da tecnologia é apresentarmos, mesmo que resumidamente, uma das análises feitas por Feenberg. O Minitel é um caso que pode exemplificar isso. ${ }^{15}$ Sabe-se que tal artefato foi proposto pelo governo francês, na tentativa de promover o desenvolvimento tecnológico quanto ao uso da informação. Encabeçado pela empresa telefônica francesa, ela propôs um sistema, denominado inicialmente como "Teletel" e desenvolvido nos anos 80, que seria um projeto para fazer com que a França entrasse na "era da informação". Nesse sentido, na tentativa de formular um aparelho que se diferenciasse das características apresentadas por objetos de escritório, surgiu

15 Esse caso do Minitel aparece em vários textos de Feenberg. No sentido de explicar como isso se fundamenta na teoria do duplo aspecto, em especial, consideraremos o que é desenvolvido em: FEENBERG, 2010b; FEENBERG, 2010c.

\begin{tabular}{|l|l|l|l|c|}
\hline Rovista Dialectus & Ano 10 & n. 23 & Maio - Agosto 2021 & p. 33 - 53 \\
\hline
\end{tabular}


o Minitel. Com um aspecto mais doméstico, tal aparelho relacionava-se a um sistema de informação, no qual o usuário podia acessar dados telefônicos.

Contudo, houve a subversão do uso do Minitel previsto inicialmente: “os usuários manipularam a rede na qual eles foram inseridos e alteraram seu funcionamento, introduzindo comunicação humanizada em uma escala onde apenas a distribuição centralizada de informações havia sido planejada" (FEENBERG, 2010b, p. 91). O que está em questão é que o aparelho recebeu uma interpretação inicial a partir de sua funcionalidade e que foi modificada no contado com os usuários. Inicialmente o governo francês demandou a elaboração de um aparelho no sentido de desempenhar um determinado tipo de função: permitir acesso às informações telefônicas. Tal objetivo viria ao encontro da necessidade de desenvolvimento da França, pois facilitaria o acesso a dados (como os telefônicos), tentando estimular um tipo de desenvolvimento comercial e econômico a partir disso. Assim, a pessoa poderia requerer tal tecnologia independentemente da sua condição socioeconômica. Entretanto, após o contato com os usuários, a tecnologia dos Miniteis "acabou recebendo um direcionamento cujos planejadores e responsáveis jamais tinham imaginado" (FEENBERG, 2010c, p. 128). O que aconteceu foi que os usuários deram outro uso ao aparelho que não estava ligado às intenções comerciais iniciais. Eles encontraram no aparelho Minitel um modo de trocar informações entre os próprios usuários, cujos conteúdos não estavam relacionados ao âmbito comercial. Tal subversão de uso do aparelho seria um exemplo de que a compreensão de uma tecnologia não se esgota na sua funcionalidade técnica; e buscar esses novos modos de uso, no sentido mais humanizado, pode ser uma das táticas para democratizar a tecnologia. Feenberg denomina essa busca como racionalidade subversiva.

Enfim, no caso do Minitel, como a teoria do duplo aspecto está pressuposta? De imediato é possível dizer que a subversão do uso inicial previsto representa a manifestação da possibilidade de uma interpretação, por parte dos usuários, de algo não observado pelos técnicos, mas que já estava presente no aparelho desde o início de seu desenvolvimento. A racionalidade funcional, descontextualizada, reduziu o aparelho ao uso, considerando unicamente o acesso a informações que potencializaram transações comerciais. Eles não perceberam que, ao contextualizar o aparelho, nele havia a possibilidade de utilizá-lo para a comunicação em um sentido mais geral. Isso representa propriamente a ideia de que o modo de ser do aparelho encerrava em si valores sociais que não poderiam ser compreendidos em um sentido descontextualizado. Em outra palavras, nesse exemplo, há elementos da racionalidade funcional proposta pela empresa, porém o aspecto social do uso das tecnologias, por parte dos

\begin{tabular}{|l|l|l|l|l|}
\hline Qevista Dialectus & Ano 10 & n. 23 & Maio - Agosto 2021 & p. 33 - 53 \\
\hline
\end{tabular}


usuários franceses, revelou que o Minitel continha nele uma significação social muito diferente do previsto. Isso potencializou um redirecionamento do desenvolvimento do aparelho, tanto do projeto inicial do Teletel quanto do próprio Minitel. Isso Feenberg caracteriza como a passagem de uma concepção fria para uma mais quente, considerando elementos humanizados da tecnologia:

\footnotetext{
E, uma vez que a comunicação se tornou a principal razão do funcionamento do sistema, a sua definição social foi radicalmente transformada. A partir da imagem original de uma mídia fria, baseada quase completamente em transações impessoais entre usuários e máquinas, o Teletel evoluiu na direção de uma nova imagem, uma imagem quente, baseada na comunicação entre seres humanos. Pequenas empresas de telemática refizeram o Teletel, transformando-o em um instrumento dedicado à comunicação humana. Assim, desenharam programas capazes de gerenciar um grande número de usuários que trocavam mensagens simultaneamente, no lugar de simplesmente receberem informações, além de criarem também um novo tipo de interface. (FEENBERG, 2010c, p. 129-130).
}

Esse redirecionamento da tecnologia permite afirmar que ela não é, a partir de sua natureza, nem neutra, quanto aos valores sociais, nem determinista, uma vez que pode ser redirecionada a partir do que a própria sociedade apresenta como valor a ser preservado.

Portanto, assim como uma concepção não neutra da tecnologia, uma concepção não determinista da tecnologia também é importante para os propósitos de Feenberg. Ao lembrarmos que há nisso uma relação com a própria natureza da tecnologia, a teoria do duplo aspecto se manifesta como um ponto fundamental para a crítica de tais conceitos. É a partir de uma abordagem adequada do ser dos objetos que a neutralidade e o determinismo são combatidos. Logo, qualquer avaliação de novas tecnologias deve levar em consideração tal dualidade. Esse será o exercício a ser feito na sequência, ao considerarmos um exemplo específico de aplicação da filosofia da Feenberg, a saber, avaliaremos o uso da tecnologia de impressão 3D na educação, pressupondo as demandas vindas da teoria do duplo aspecto.

\section{ASPECTOS HISTÓRICOS, TÉCNICOS E SOCIAIS DA TECNOLOGIA DE IMPRESSÃO 3D}

\subsection{Aspectos históricos}

Ao se delinear os aspectos históricos da impressão 3D, inicialmente, é preciso mencionar que a tecnologia de impressão 3D é algo recente na história da humanidade. Considera-se Charles Hull o precursor do modo de construir objetos por camadas, cuja técnica

\begin{tabular}{|l|l|l|l|l|}
\hline Q & Ano 10 & n. 23 & Maio - Agosto 2021 & p. 33 - 53 \\
\hline
\end{tabular}


foi denominada como estereolitografia ${ }^{16}$. Especificamente, essa técnica pode ser descrita da seguinte maneira:

[Ela] consiste em solidificar camadas de um fotopolímero (similar a uma resina), utilizando a luz. As impressoras mais atuais desse tipo utilizam um aparato simples: um projetor de alta resolução, igual aos utilizados em apresentações de slides, projetando imagens sobre um recipiente repleto de resina e com uma plataforma que se movimenta verticalmente. O processo inicia-se com essa plataforma quase no topo do balde; uma imagem é projetada por alguns segundos sobre a fina camada de resina causando uma solidificação com o formato da imagem projetada. Em seguida essa plataforma desce alguns micrômetros e novamente uma imagem levemente diferente da anterior é projetada para solidificar mais uma camada; assim, de camada em camada, uma solidificada sobre a outra, forma-se o objeto tridimensional. (AGUIAR \& YONEZAWA, 2014, p. 14).

Na citação, podemos identificar alguns elementos que devem ser enfatizados, visto que eles nos ajudam a compreender a técnica empregada. A princípio, é necessário dizer que o conceito de fotopolímero está relacionado ao resultado de uma alteração física do contato que o polímero tem com a exposição da luz. Os polímeros podem ser naturais ou não, e eles contêm macromoléculas que são constituídas a partir de moléculas menores denominadas como monômeros. Em seguida, há a compreensão de que as impressoras mais recentes usam a simples tecnologia que projeta a imagem no recipiente. Dito de outra forma, Aguiar e Yonezawa relatam que a imagem se solidifica numa fina camada de resina, que é a substância utilizada para produzir produtos de plásticos. $\mathrm{O}$ fato de tal processo se repetir é o que possibilita a solidificação de mais camadas, produzindo o objeto impresso em três dimensões.

O precursor da impressora 3D, Charles Hull, ganhou notoriedade ao produzir a primeira impressora 3D, na década de $1980^{17}$. Sabe-se que ele usou a luz ultravioleta para revestir a sua mesa e que ele patenteou essa técnica da estereolitografia. Ele passou, então, a comercializar o seu produto quando fundou a 3D Systems Corporation ${ }^{18}$. Acredita-se que, possivelmente, o primeiro artefato da impressora 3D foi a construção de uma lâmpada. Isso foi seguido por outros objetos com partes em "plástico".

Outro aspecto a ser mencionado é o da virtualidade da impressão 3D. Trata-se do aspecto digital, ligado ao mundo computacional. Existem softwares, programas e plataformas, como o Tinkercad, que oferecem a possibilidade da modelagem tridimensional. É comum que os arquivos salvos, com tal finalidade, possuam a extensão .STL (cujo significado e origem não

${ }^{16}$ Em inglês stereolithography, que posteriormente passou-se a ser mencionada pelas siglas SL ou SLA. Acerca disso: cf. MELCHELS, 2012.

17 Ibidem.

18 Ibidem.

\begin{tabular}{|l|l|l|l|l|}
\hline Qovista Dialectus & Ano 10 & n. 23 & Maio - Agosto 2021 & p. 33 - 53 \\
\hline
\end{tabular}


se tem consenso e ao qual muitos mencionam que seja oriundo da palavra: "STereoLithography"):

\begin{abstract}
A estrutura tridimensional (3D) é (virtualmente) fatiada em camadas de uma espessura específica que são usadas na fabricação processo (geralmente na faixa de $25100 \mathrm{~mm}$ ). Esses dados são, em seguida, carregados para o aparelho de estereolitografia (SLA) e a estrutura é fabricada camada por camada. A fabricação de objetos 3D pelo SL é baseada na solidificação espacialmente controlada de uma resina líquida por polimerização fotoiniciada. Usando um laser controlado por computador feixe ou um projetor de luz digital com um computador estágio de construção, um padrão é iluminado na superfície de uma resina. Como resultado disso, a resina no padrão é solidificada a uma profundidade definida, até aderir à camada anterior. Em seguida, a plataforma com a estrutura anexada é movida para longe da superfície com uma distância igual a uma camada espessura, após a qual a camada construída é recoberta com resina líquida. Este ciclo é repetido muitas vezes até que um objeto sólido tridimensional seja obtido a partir do qual o excesso de resina é drenado e lavado. (MELCHELS, 2012, p. 173).
\end{abstract}

Melchels explica, nessa passagem, todo o processo da fabricação de um objeto cuja estrutura é tridimensional (3D). Há um detalhe importante ainda, da citação, a ser enfatizado: o objeto em fase de construção está sob controle de um computador. Essa relação faz parte das discussões sobre o uso da impressora 3D.

Ainda do ponto de vista do desenvolvimento histórico, para o pesquisador Jakus (2019, p. 2-5), a tecnologia de impressão 3D pode ser dividida em cinco, ou até seis momentos: $1^{\circ}$ ) entre os anos 1970 e 1980, que tem como base os precursores da tecnologia assim chamados, por ele, de "fabricação de proto aditivo"; $2^{\circ}$ ) entre os anos 1980 a 1990, que tem como característica o surgimento das três tecnologias de impressão 3D e a criação da primeira empresa do ramo; $3^{\circ}$ ) de 1990 a 2005, no qual há um amadurecimento da tecnologia e o aperfeiçoamento realizado pelas empresas privadas; $4^{\circ}$ ) de 2005 a 2012, período marcado pela abertura ao grande público; 5 $5^{\circ}$ a partir de 2012/2013 até os dias atuais, em que novas tecnologias adicionais junto com o apoio de governo federal; $6^{\circ}$ ) momento presente, no qual o foco é desenvolver novos materiais avançados.

\title{
3.2 Definindo tecnicamente a impressora 3D
}

Sob o aspecto funcional, a impressora 3D tem como finalidade a produção de objetos que possuam três dimensões. Contudo, como defini-la precisamente, ainda do ponto de vista técnico? Diante de tal questão, vemos que a resposta se mostra como algo difícil de ser estabelecido. Para isso, basta observar que vários aspectos parecem ser necessários para a análise técnica da impressora 3D.

\begin{tabular}{|c|c|c|c|c|}
\hline Qevista Dialectus & Ano 10 & n. 23 & Maio - Agosto 2021 & p. $33-53$ \\
\hline
\end{tabular}


Inicialmente, o objeto precisa ser virtual. Isso ocorre através da modelagem da arte em um software, que gera algum tipo de arquivo a ser salvo no disco rígido de armazenamento do computador, ou em outras fontes de armazenamento, como é caso dos espaços virtuais nas nuvens, pendrives, dentre outros.

Contudo, além da relação com o mundo virtual, há uma profunda ligação com a manipulação de materiais, ou matérias primas, o que exige um sólido conhecimento de suas propriedades, sejam físicas ou químicas, no sentido de poderem ser avaliados como recursos para as constituições dos objetos a serem impressos. É nesse sentido que se sustenta, em Figueroa et al. (2013, p. 48-98), que "a impressão 3D é uma tecnologia aditiva em que objetos 3D são criados usando técnicas de camadas de diferentes materiais, como plástico, metal etc.”. Não basta conhecer o processo de impressão, há a necessidade de avaliar os materiais ali envolvidos.

Além dessa definição, podemos pensar sobre algumas questões inevitáveis que estão ligadas ao aspecto técnico. A impressão 3D é um instrumento independente do operador? Para respondermos a isso, devemos retomar a ideia de funcionalidade apresentada inicialmente. Sua funcionalidade exige que alguém saiba realizar a modelagem virtual dos objetos. Sem um conhecimento nesse aspecto não há impressão 3D. Assim, qual é o papel desempenhado pelo operador na própria definição da impressão 3D?

Sobre outra perspectiva de análise, podemos ainda nos questionar a respeito de qual parte do equipamento abriga o elemento fundamental para a sua definição: o software, o aparelho modelador de materiais ou o conjunto que envolve também o computador? O que sabemos é que sem o operador (artista, engenheiro), o software, o aparelho e o computador não há impressão 3D, mesmo que eles não sejam suficientes para compreender a produção da impressão como um todo. Se considerarmos que a impressão 3D consiste nos produtos ou materiais, como deixar de lado todos os elementos anteriormente citados?

Dado esse conjunto de questões, não é possível estabelecer uma definição de impressão 3D de modo simples. Os aspectos técnicos levam à necessidade de condensar uma gama de elementos. É exatamente isso que Jakus realiza ao tentar explicar o que é a tecnologia de impressão 3D:

Independentemente do processo de impressão 3D utilizado, o resultado final dependerá da aplicação e interação de três componentes principais: hardware, software, e o material (...). A atenção é mais frequente dada ao hardware (a própria impressora 3D), que cria o objeto. No entanto, é o software que define a forma do objeto e a maneira como o hardware constrói o objeto e o material que define a funcionalidade dos objetos que são absolutamente vitais para o sucesso da aplicação 3D impressão em qualquer cenário. A tríade está fechada dentro de "treinamento, 
habilidade e experiência do usuário" porque a impressão 3D (ainda) não é um processo automático; isso requer treinamento, habilidade e experiência do usuário como qualquer outro processo de manufatura. O software utilizado para criar e preparar um arquivo digital para impressão 3D abrange tudo, desde a aquisição de imagens 3D, design auxiliado por computador e programas de transformação .STL. (JAKUS, 2019, p. 9).

Nesse trecho é possível identificar a tentativa de evitar a redução da compreensão do que é a impressão 3D a um de seus elementos técnicos. Não envolve somente o hardware, ou seja, o aparelho no qual o objeto impresso surge. Muito menos, ela não se resume no software, o programa com o qual se pode virtualmente pensar os objetos a serem impressos. $\mathrm{O}$ material impresso, em si, também não resume todos os constituintes envolvidos no processo. Em outras palavras, a própria definição técnica, acerca de tal tecnologia, exige uma abordagem ampla, que envolve vários setores técnicos. Assim, como compreender os elementos sociais envolvidos na tecnologia 3D, uma vez que a própria compreensão técnica exige um gama diversa de elementos técnicos, resultantes de linhagens técnicas distintas?

\subsection{O uso da impressora $3 D$ na educação}

Quando temas educativos são abordados, o uso de novas tecnologias é uma questão recorrente. ${ }^{19} \mathrm{O}$ que parece é que profissionais da educação têm realizado uma tentativa de dinamizar o processo de ensino e aprendizagem. Parece que se vê nas tecnologias, além da possibilidade de atrair a atenção dos alunos, um caminho para efetivar um processo de ensino/aprendizagem. É preciso levar em consideração que muitos alunos, de fato, têm acesso a vários recursos tecnológicos, como por exemplo, celulares, tablets, notebooks, videogames etc. Trazer esses recursos para o âmbito da educação pode, em algum sentido potencializar o ensino, uma vez que os próprios objetos tecnológicos podem ser um caminho para a reflexão dos estudantes sobre o uso da tecnologia na sociedade. ${ }^{20}$

Nesse contexto, podemos nos voltar ao uso da impressora 3D. Em sua história, a tecnologia de impressão 3D teve uma relação não tão expressiva de seu uso. Como visto acima, como Jakus sugere, somente a partir de uma $4^{\mathrm{a}}$ etapa do desenvolvimento da impressão 3D, a

19 Tal afirmação pode ser exemplificada com a análise que Aguiar (2008, p. 63) faz do uso de Tecnologias de Informação e Comunicação (TICs) na educação. Considerando a necessidade de repensar a prática pedagógica, a autora acena para uma possível vantagem do uso de tecnologias, por exemplo, no ensino da matemática: "O uso das novas tecnologias propicia trabalhar em sala de aula com investigação e experimentação na Matemática, considerando que permite ao aprendiz vivenciar experiências, interferir, fomentar e construir o próprio conhecimento". Para mais uma análise sobre a necessidade do emprego de tecnologia na educação, agora em um sentido mais amplo: cf. MERCADO, 2002.

20 Acerca de um exemplo da presença da tecnologia no ensino, no sentido de saber se há a realização da emancipação de alunos: cf. SEPÉ, 2017.

\begin{tabular}{|c|c|c|c|c|}
\hline Q $R$ ovista Dialectus & Ano 10 & n. 23 & Maio - Agosto 2021 & p. 33 - 53 \\
\hline
\end{tabular}


partir de 2005, que ela passa a atingir um grande público, ou seja, com o passar dos anos, a impressora 3D tem se tornado cada vez mais popular. A sua presença em sala de aula já é algo visível. Já existem investigações de como compreender o seu uso no processo educativo. ${ }^{21}$

Assim, ao se ter como referência a filosofia da tecnologia de Feenberg, em especial o duplo aspecto, o uso da impressão 3D pode ser a oportunidade de promover, entre os estudantes, reflexões que lhes permitam desenvolver um ponto de vista mais crítico quanto à presença da tecnologia em nossa sociedade. Há, por exemplo, o desavio de evidenciar de que modo, a partir seus aspectos fundamentais, não se sustenta uma concepção determinista da tecnologia. Uma postura determinista da impressão 3D consistiria simplesmente em dar a importância à aprendizagem de sua manipulação, uma vez que o mundo do trabalho demanda por operadores de tais máquinas. O próprio trabalho seria algo modelado pelo surgimento e evolução da tecnologia de impressão 3D. No entanto, muito mais do que ensinar os alunos a operá-la, dada uma demanda profissional, o seu uso na educação pode oportunizar aos alunos as condições para repensar seu estatuto de cidadãos, como pessoas inseridas em uma comunidade e que podem decidir sobre os rumos de desenvolvimento dessa tecnologia.

Contudo, é necessário enfatizar a questão sobre os caminhos a serem seguidos para realizar, no sentido proposto por Feenberg, uma democratização da tecnologia de impressão 3D: de que forma o seu uso pode de fato ser abordado de modo a promover uma nova visão sobre a própria natureza da tecnologia? Como visto na seção anterior, tal tecnologia contém uma racionalidade funcional. A partir da teoria do duplo aspecto, mesmo que ela não esgote o que é tal tecnologia, a funcionalidade é algo importante na compreensão da impressão 3D. No entanto, seu aspecto social também deve ser compreendido. Uma possível resposta à questão seria considerar os usos previstos, em seu projeto inicial, e os não previstos para essa tecnologia. Após isso, conseguiremos ponderar as implicações para seu uso no contexto da educação.

\subsection{Os elementos sociais na impressão 3D: usos previstos e não previstos}

Na abordagem, acima, do exemplo do computador Minitel, tentou-se mostrar como Feenberg interpretou a subversão do uso de tal equipamento. Havia um projeto que previa um uso orientado por um fim. Contudo, quando ele entra em contato com as pessoas, revelam-se outras possibilidades, mostrando que o Minitel se constituía por uma natureza social diferente do que foi previsto, isto é, ele continha em si algo de social que se harmonizava com o interesse

21 Para um exemplo disso: cf. BATISTA e SANTOS, 2020. 
das pessoas, que não era o comercial, como pressupunham seus idealizadores. Trata-se de um exemplo de modificação social do significado, bem como de suas diretrizes norteadoras, para seu aperfeiçoamento. Outro exemplo de Feenberg, quanto à intervenção social de objetos técnicos, encontra-se nas, já mencionada aqui, caldeiras de barcos a vapor. Esse era o principal meio de locomoção nos Estados Unidos, no século XIX. Contudo, uma vez que eram instáveis, provocando inúmeras mortes por explosões, viu-se a necessidade de regulamentação no sentido de promover a segurança das pessoas. Feenberg compreende isso como um código social da técnica, visto que direciona o modo como será aperfeiçoado um objeto técnico, com vista a demandas estabelecidas a partir do social. ${ }^{22}$ Assim, tais caldeira se direcionaram para um caminho de desenvolvimento técnico não previsto inicialmente.

Ora, de modo análogo, podemos afirmar que algo semelhante acontece com a tecnologia de impressão 3D. Segundo Matias e Rao (2015, p. 551), após seu desenvolvimento nos anos 80, a impressão 3D, por cerca de 20 anos, desenvolve-se silenciosamente de modo a ser "utilizada principalmente por designers e engenheiros no espaço de negócios". Podemos interpretar isso no sentido de que, após as primeiras patentes de tal tecnologia, iniciadas por Charles Hull, a impressão 3D foi compreendida como um modo de potencializar a confecção de artefatos, com o intuído de ter implicações comerciais. A principal interação com o meio social seria aquela ligada à finalidade comercial.

Contudo, outro elemento que necessita ser ressaltado, considerando sua história, é que o uso da tecnologia de impressão 3D, desde as primeiras impressões, tem ganho outras formas a partir do seu uso pelas pessoas. O desenvolvimento técnico dessa tecnologia tem sido moldado por áreas não previstas anteriormente. Esse é o caso de aplicações na área da saúde, como os implantes utilizados em cirurgias ${ }^{23}$ e, em um contexto mais recente, como a produção de máscaras (face Shields) e ventiladores de código aberto para arejar ambientes, durante a pandemia da COVID-19 ${ }^{24}$, tentando evitar a propagação do vírus causador da doença. Isso nos indica que há interesses sociais que inicialmente não foram pensados e podem ofertar à tecnologia de impressão 3D uma nova forma de seu uso. Assim, ao se abordar interesses sociais não previstos, podemos indicar que essa tecnologia se enquadra em mais um exemplo para negar a visão determinista e neutra da tecnologia. Tal impressora não se desenvolve unicamente como um objeto técnico, tendo em vista certos valores instrumentais como, por exemplo, os de

22 Cf. FEENBERG, 2019, p. 51.

23 Cf. KALASKAR, 2017, p. 23.

24 Cf. BELHOUIDEG, 2020, p. 4-6.

\begin{tabular}{|c|c|c|c|c|}
\hline Rovista Dialectus & Ano 10 & n. 23 & Maio - Agosto 2021 & p. 33 - 53 \\
\hline
\end{tabular}


durabilidade, resistência e performance. Os elementos sociais de vários âmbitos, como é o caso também, da aplicabilidade da impressão 3D na construção de $\operatorname{casas}^{25}$, podem interferir no modo de interpretá-la. Considerando especificamente esse exemplo, pergunta-se: a necessidade por moradias populares não poderia revelar com mais intensidade uma natureza social, ligada a valores democráticos, da própria impressão 3D? A resposta parece ser que sim. Esse é provavelmente um outro contexto - para a investigação das potencialidades de impressão 3D não profundamente explorado. Entretanto, se é possível dizer que uma interpretação funcional inicial tem sido subvertida, e por se tratar de uma tecnologia ainda recente, é sinal de que cabe investigar os usos sociais que lhe correspondem. Trata-se de algo ainda aberto, algo que merece reflexão. Na perspectiva de Feenberg, já se pode indicar que ela possui uma natureza dual. Contudo, a impressão 3D é muito recente na história da tecnologia. É um caso que deve ser estudado no sentido de compreender a amplitude de sua dualidade, tanto funcional quanto social.

\section{CONCLUSÃO}

Em um primeiro momento, investigamos de que modo o pensamento de Feenberg, sobre a tecnologia, compromete-se com uma concepção dual da natureza dos objetos técnicos. Não se pode conceber tais objetos sem que, ontologicamente, exista uma perspectiva funcional ou técnica, de um lado, e algo social (constituído por valores compartilhados ou não pela sociedade), de outro lado. Sua filosofia, baseada em uma análise crítica, avança no combate de concepções que tratam os objetos como neutros, quanto a valores sociais. Porém, também se recusam concepções determinantes de modos de vida social, no sentido de mão única, do aspecto técnico para o social. Feenberg nega o determinismo social, por parte da tecnologia, já que ela pode sofrer redirecionamentos a partir dos valores que expressam os interesses das pessoas. Tal cenário filosófico, ao ser aplicado ao caso da tecnologia de impressão 3D, levounos ao questionamento sobre as condições ou pressupostos que necessitam ser levados em consideração, quanto ao contexto educativo. Desse modo, podemos concluir, indicando alguns pontos fundamentais a respeito disso.

Em primeiro lugar, o educador que usar tal tecnologia deve ter consciência de que um uso previsto não implicará em sua definição absoluta e, muito menos, não esgota a dimensão

25 Cf. HAGER, 2016, p. 293-294.

\begin{tabular}{|l|l|l|l|c|}
\hline Revista Dialectus & Ano 10 & n. 23 & Maio - Agosto 2021 & p. $33-53$ \\
\hline
\end{tabular}


social ali envolvida. Há a necessidade de ter uma atitude prudente, pois os usos sociais conhecidos e previstos, ligados à impressão 3D, implicam em um modo de vida que, por sua vez, merece ser avaliado. Os exemplos de subversão de uso, mesmo que poucos - dada a recente história dessa tecnologia -, mostram que os valores sociais impregnados na tecnologia de impressão 3D podem ainda ser revelados. Há a possibilidade de investigá-los na própria contextualização do uso na sociedade. Feenberg diria, nesse caso, que a dimensão social, ontologicamente presente na impressão 3D, é algo a ser aprofundado em um processo de interação social, democraticamente estabelecido, na medida em que se formulam diálogos investigativos, considerando as pessoas diretamente afetadas pelo seu uso.

Além disso, cabe lembrar que Feenberg não excluí o aspecto funcional. Esse é um dos elementos definidores da tecnologia, sendo importante também compreendê-la. No caso da impressão 3D, para a sua aplicação na educação, conhecer o aspecto funcional não é algo a ser menosprezado. No entanto, o que deve ser reforçado é que um educador não pode resumir a definição de tal tecnologia somente a seus aspectos técnicos. Saber operá-la não autoriza ninguém a se pôr acima de outras pessoas, pressupondo erroneamente que o conhecimento técnico esgota o elemento definidor da tecnologia de impressão 3D. Nenhuma "autoridade" técnica tem a última palavra sobre o que é uma tecnologia. Como visto, os aspectos funcionais não esgotam o ser de um objeto técnico, isto é, não o definem absolutamente. Um educador necessita saber disso para que possa ficar atento, no sentido de não atribuir, ou até mesmo propagar, noções superficiais que gerem consequência indesejadas ao meio social.

Por último, é possível acrescentar algo acerca do equilíbrio avaliativo do aspecto dual das tecnologias. Trata-se do problema de saber se, no contexto educativo, deve-se dar primazia a algum dos dois aspectos. Em outras palavras, ainda que o objetivo aqui não tenha sido o de apontar procedimentos didáticos precisos, uma vez que estamos interessados em refletir sobre a natureza da tecnologia, cabe se perguntar: qual dos aspectos da tecnologia 3D é mais importante para o educador? Esse é um ponto difícil de responder. Como vimos, uma definição a partir dos elementos técnicos se constitui como uma tarefa complexa. Não é possível dizer que a impressão 3D se resume à peça que confecciona os objetos de três dimensões, muito menos ao software - elemento digital (programa) que permite tratar virtualmente tais objetos. Contudo, essa complexidade técnica parece também dificultar a compreensão da dimensão social da tecnologia de impressão 3D. Se há uma ampla relação de elementos técnicos envolvidos, a investigação sobre a natureza social deve incluir isso também. Dito de outra forma, o uso da impressão 3D deve valorizar tanto um aspecto quanto outro. Ao mesmo tempo

\begin{tabular}{|l|l|l|l|l|}
\hline Qevista Dialectus & Ano 10 & n. 23 & Maio - Agosto 2021 & p. 33 - 53 \\
\hline
\end{tabular}


que se investigam os elementos sociais, deve-se investigar os aspectos técnicos e vice-versa. Mesmo para o contexto educativo, talvez este seja o ponto mais importante a ser ressaltado aqui: há um imbricamento indissociável dos dois aspectos da tecnologia. Mesmo que seu objetivo tenha sido o de ressaltar o aspecto social dos objetos técnicos, a teoria do duplo aspecto, de Feenberg, não alcança êxito sem que se conheça ao mesmo tempo a extensão técnica envolvida nos objetos.

\section{REFERÊNCIAS}

AGUIAR, Eliane Vigneron Barreto. As novas tecnologias e o ensino-aprendizagem. In: Vértices, Rio de Janeiro, v. 10, p. 63-71, 2008. p. 65.

AGUIAR, Leonardo De Conti Dias; YONEZAWA, Wilson Massashiro. Construção de instrumentos didáticos com impressoras 3D. In: IV Simpósio Nacional de Ensino de Ciência e Tecnologia. Ponta Grossa, PR: SINECT, 2014.

BATISTA, Rayane Luzia de Andrad; SANTOS, Jarles Tarsso Gomes. O uso do geogebra e impressora $3 \mathrm{~d}$ como recurso didático para o ensino da geometria das coordenadas. Anais do $\mathbf{V}$ Congresso sobre tecnologias na educação $(\mathbf{C T R L}+\mathbf{E})$. Porto Alegre: Sociedade Brasileira de Computação, 2020, p. 208-217.

BELHOUIDEG, Soufiane. Impact of 3D printed medical equipment on the management of the Covid19 pandemic. In: The International Journal of Health Planning and Management. 2020. volume 35. September 2020. pp. 2-4.

CRUZ, Cristiano Cordeiro. Andrew Feenberg e a teoria crítica da tecnologia. In: Entre a razão e a experiência: ensaios sobre tecnologia e modernidade. Tradução de Eduardo Beira, Cristiano Cruz, Ricardo Neder. Portugal: INOVATEC, 2019, pp. 9-45

Andrew Feenberg: O desenvolvimento tecnológico é uma arena política. In: OLIVEIRA, Jelson (org). Filosofia da tecnologia: seus autores e seus problemas. Caxias do Sul, RS: Educs, 2020. pp. 105-114.

CUPANI, Alberto. A tecnologia como problema filosófico: três enfoques. In: Scientiae Studia, São Paulo, v. 2, n. 4, p. 493-518, 2004.

Filosofia da tecnologia: um convite. 3 ed. Florianópolis: Editora da UFSC, 2017.

DAGNINO, Renato Peixoto. Neutralidade da ciência e determinismo tecnológico. Campinas, SP: Editora da UNICAMP, 2008.

FEENBERG, Andrew. Da informação à comunicação: a experiência francesa com o videotexto. In: NEDER, Ricardo $\mathrm{T}$ (org.). A teoria crítica de Andrew Feenberg: racionalização democrática, poder e tecnologia. Brasília: Observatório do Movimento pela Tecnologia Social na América Latina / CDS / UnB / Capes, 2010c, pp. 119-151.

\begin{tabular}{|l|l|l|l|l|}
\hline Qevista Dialectus & Ano 10 & n. 23 & Maio - Agosto 2021 & p. 33 - 53 \\
\hline
\end{tabular}


Entre a razão e a experiência: ensaios sobre tecnologia e modernidade. Tradução de Eduardo Beira, Cristiano Cruz, Ricardo Neder. Portugal: INOVATEC, 2019.

. O que é a Filosofia da Tecnologia? In: NEDER, Ricardo T (org.). A teoria crítica de Andrew Feenberg: racionalização democrática, poder e tecnologia. Brasília: Observatório do Movimento pela Tecnologia Social na América Latina / CDS / UnB / Capes, 2010a, pp. 51-65.

. Racionalização subversiva: tecnologia, poder e democracia. In: NEDER, Ricardo T (org.). A teoria crítica de Andrew Feenberg: racionalização democrática, poder e tecnologia. Brasília: Observatório do Movimento pela Tecnologia Social na América Latina / CDS / UnB / Capes, 2010b, pp. 69-95.

Transforming Technology: a critical theory revisited. New York: Oxford University Press, 2002.

FIGUEROA, Nadia; DONG, Haiwei; SADDIK, Abdulmotaleb El. From Sense to Print: Towards Automatic 3D Printing from 3D Sensing Devices. In: 2013 IEEE International Conference on Systems, Man, and Cybernetics, 2013, Manchester, United Kingdom. pp. 4897-4904.

HAGER, Izabela; GOLONKA, Anna; PUTANOWICZ, Roman. 3D Printing of Buildings and Building Components as the Future of Sustainable Construction? In: International Conference on Ecology and new Building materials and products, ICEBMP 2016. Černá Hora, República Tcheca: Procedia Engineering. v. 151, 2016. pp. 292-299.

JAKUS, Adam E. An introduction to 3D Printing - Past, Present and Future Promise. In: DIPAOLLA, Matthew; WODAJO, Felasfa M. 3D Printing in Orthopaedy Surgery. St. Louis, Missouri: Elsevier, 2019.

KALASKAR, Deepkak. M. 3D Printing in Medicine. London: Woodhead Publishing, 2017.

MATIAS, Elizabeth; RAO, Bharat. 3D printing: On its historical evolution and the implications for business. Portland International Conference on Management of Engineering and Technology (PICMET). 2015, pp. 551-558

MELCHELS, Ferry P. W. Celebrating three decades of stereolithography. In: Virtual and Physical Prototyping. Vol. 7, n. 3, p. 173-175, set. 2012.

MERCADO, Luís Paulo Leopoldo. Formação docente e novas tecnologias. In: MERCADO, Luís Paulo Leopoldo (org.). Novas tecnologias na educação: reflexões sobre a prática. Maceio: EDUFAL, 2002. pp. 11-28.

SEPÉ, Cláudia Presser. A educação em tempos de novas tecnologias: no limite entre a emancipação e a exclusão. In: AMARAL, Sergio Ferreira; GARCIA, André Oliveira. Tecnologia e Competências: das reflexões às possibilidades. LANTEC - UNICAMP, 2017, pp. 16-26.

\begin{tabular}{|c|c|c|c|c|}
\hline Q Rovista Dialectus & Ano 10 & n. 23 & Maio - Agosto 2021 & p. $33-53$ \\
\hline
\end{tabular}

